\title{
DETERMINATION OF THE RADIOCARBON AGE OF PARCHMENT OF THE VINLAND MAP
}

\author{
D J Donahue ${ }^{1}$ J S Olin ${ }^{2} \bullet \mathrm{G} \mathrm{Harbottle}^{3}$
}

ABSTRACT. The Vinland Map, drawn on a $27.8 \times 41.0 \mathrm{~cm}$ parchment bifolium, is housed in the Beinecke Rare Book and Manuscript Library at Yale University. In the northwest Atlantic Ocean, it shows "the Island of Vinland, discovered by Bjarni and Leif in company." Skelton, Marston, and Painter (Skelton et al. 1965, 1995) firmly argued the map's authenticity, associating it with the Council of Basle (AD 1431-1449), that is, half a century before Columbus's voyage. Nevertheless, vigorous scholarly questioning of the map's authenticity has persisted (Washburn 1966; McCrone 1974; Olin and Towe 1976; Cahill et al. 1987; McCrone 1988; Towe 1990). We have determined the precise radiocarbon age of the map's parchment by accelerator mass spectrometry (AMS). The one-sigma calibrated calendrical date range is AD $1434 \pm 11$ years: the $95 \%$ confidence level age range is $\mathrm{AD} 1411-1468$.

\section{INTRODUCTION}

If the Vinland Map (Figure 1) is authentic, it is the first known cartographic representation of North America and its date is important in establishing the history of European knowledge of the lands bordering the western North Atlantic. It also raises the deeper question of Columbus's own possible awareness of that earlier knowledge (Washburn 1995). The map's account of the Norse voyage of discovery also differs significantly from that of the sagas (Magnusson and Palsson 1965) in that Bjarni and Leif are said to have voyaged together rather than separately.

These questions point out the significance of scientific evidence in this case. They are questions of historical consequence. In undertaking the measurement of the radiocarbon content of the parchment, we were aware that dates from the 16th century onward would suggest the map to be a forgery. A 15th century date would be less conclusive, but would constitute a major contribution to the known facts concerning the authenticity of the map. Obviously, a 15th century date per se neither refutes nor proves authenticity, but is necessary for authenticity.

In 1972, Yale commissioned microscopist Walter McCrone to examine minute samples of ink from the Vinland Map. McCrone reported $(1974,1988)$ that the ink contained very substantial quantities of titanium dioxide in the anatase crystalline modification. Because precipitated anatase only became commercially available about 1920, its presence in the ink satisfied McCrone that the map must be a 20th century forgery. Yale announced in 1974 that the map "may be a forgery".

Two very different rebuttals have been made to McCrone. First, Cahill et al. (1987) at the University of California in Davis published in-situ analyses of the map ink at 159 locations by PIXE (proton induced x-ray emission). They demonstrated that titanium is only present at trace levels - orders of magnitude smaller than McCrone's estimates but very much in line with the levels found in numerous other medieval inks tested (Cahill et al. 1987). The paper by Cahill et al. prompted a reply from McCrone (1988): a valuable summary of this response compiled by Cahill and Kusko appears in the 2nd edition of Skelton et al. (1995).

\footnotetext{
${ }^{1}$ Department of Physics and NSF-Arizona AMS Laboratory, University of Arizona, Tucson, Arizona 85721, USA. Corresponding author. Email: djd@physics.arizona.edu.

${ }^{2}$ Smithsonian Center for Materials Research and Education, Smithsonian Institution, Washington, D.C. 20560, USA

${ }^{3}$ Chemistry Department, Brookhaven National Laboratory, Upton, New York 11973 and Department of Geosciences, Stony Brook University, Stony Brook, New York 11790, USA
} 


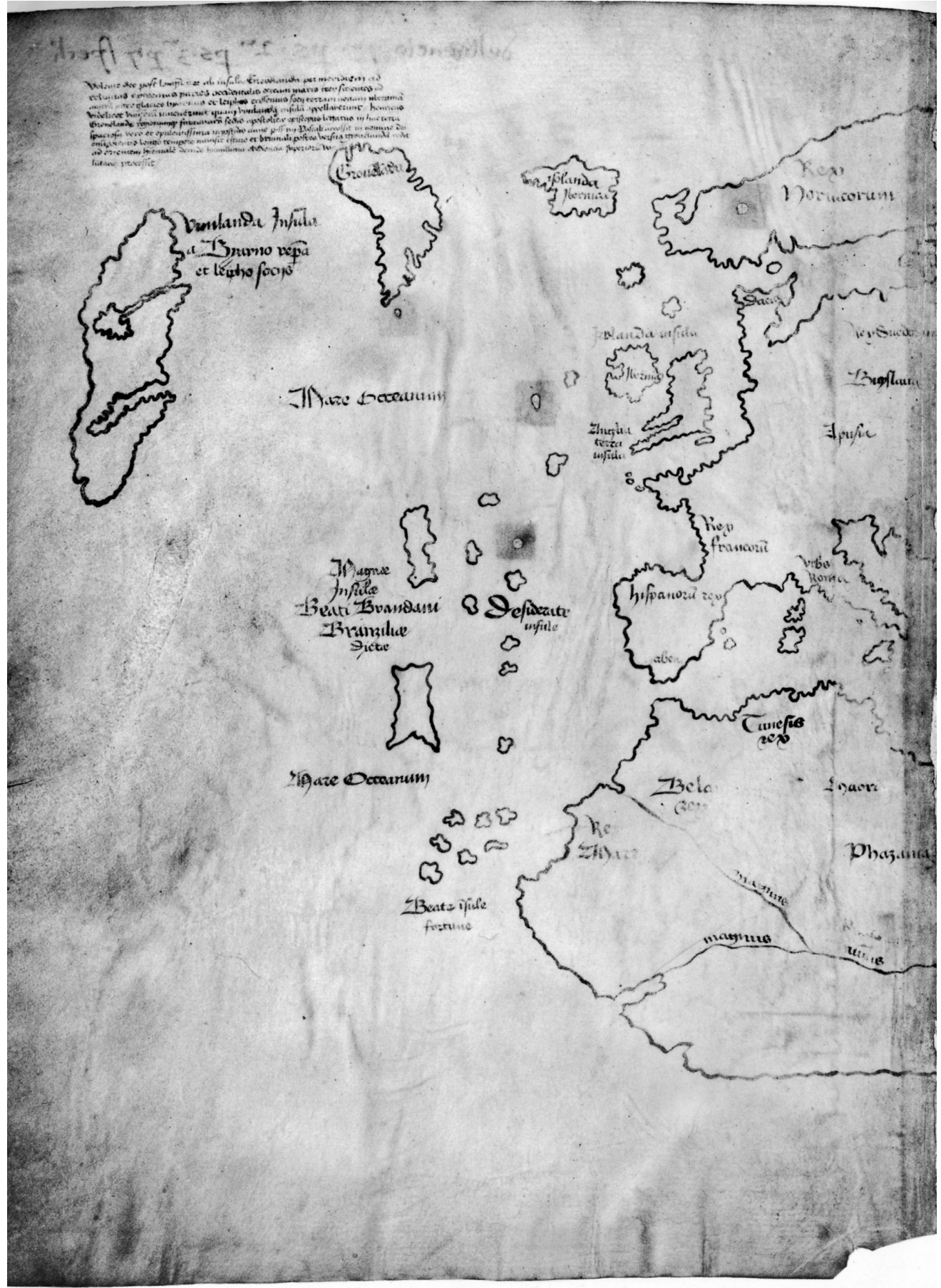

Figure 1 The Vinland Map. Reprinted with permission. () 1965 Yale University Press. All rights reserved. 


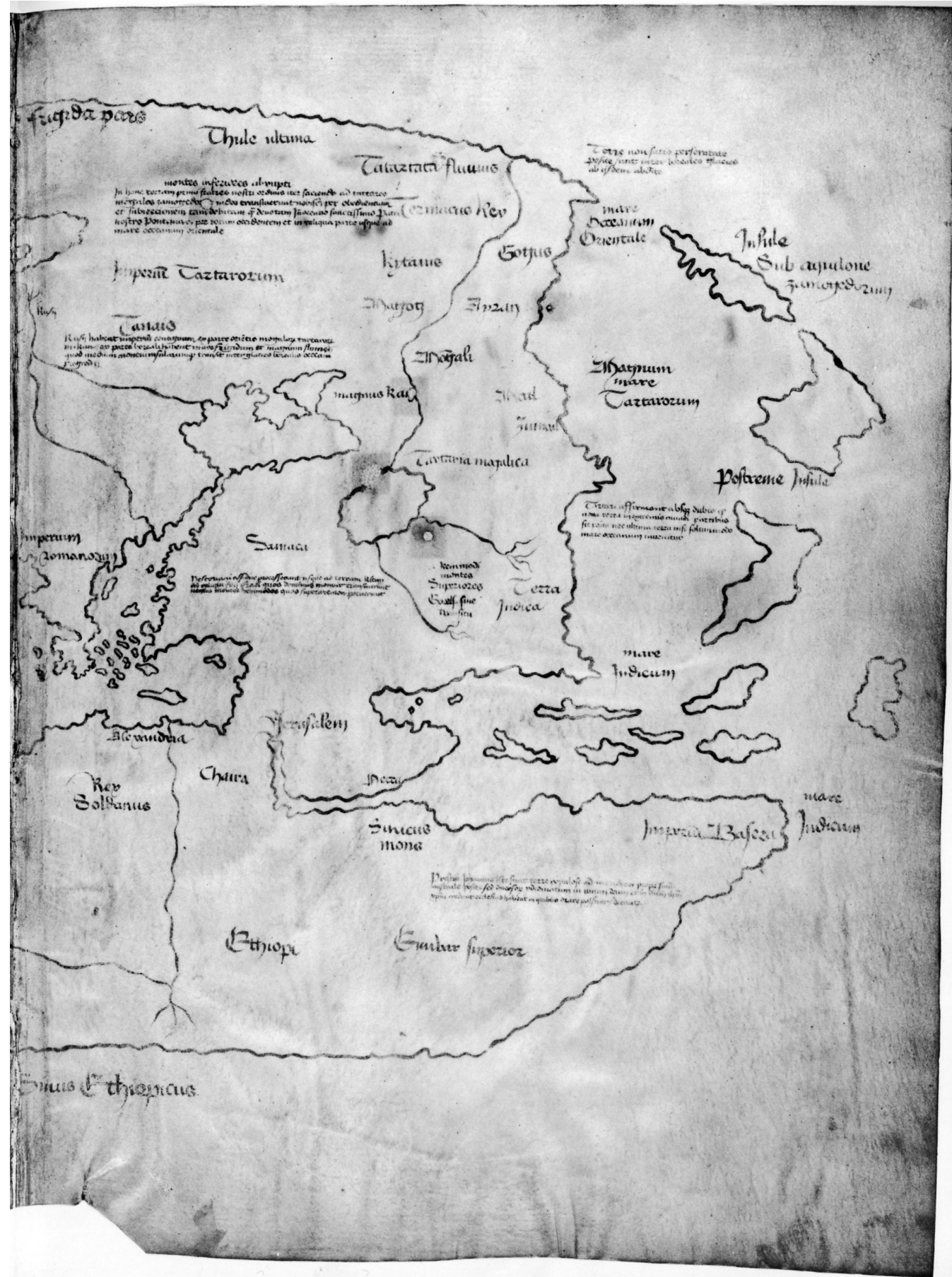

From The Vinland Map and the Tartar Relation (1965) by R A Skelton, T E Marston, and G D Painter. First edition, p 17. 
Recently, Olin has published an explanation of why the presence of anatase need not prove that the map is a forgery (Olin 2000). The analysis of authentic medieval inks would be necessary to confirm this explanation, but to date the presence of anatase has not been established conclusively as proof of forgery. Olin's paper also reports that when examined in connection with historical evidence regarding ink production, the elemental composition (as reported by McCrone and by Cahill) supports the possibility that the ink is medieval. The historical evidence that the map's ink composition could be compatible with a medieval origin further underscores the importance of determining a precise ${ }^{14} \mathrm{C}$ date for the map's parchment. It would also be desirable to determine the ${ }^{14} \mathrm{C}$ content of the ink, but the required sample size for such a measurement would be prohibitively large.

\section{PROCEDURES AND RESULTS}

In February 1995, a strip of parchment with a mass of $28.8 \mathrm{mg}$ was cut from the Vinland Map at the Beinecke Library at Yale University for measurement at the NSF-Arizona Accelerator Mass Spectrometer Laboratory in Tucson, Arizona, where it was assigned the number AA 16567. The sample was cut from the lower right corner, far from the ink marking on the map. In the laboratory, the parchment was sequentially cut into several smaller samples and these subsamples were subjected to chemical cleaning, combustion to carbon dioxide, conversion to graphite, and analysis for ${ }^{14} \mathrm{C}$ content. All processes, from chemical cleaning to ${ }^{14} \mathrm{C}$-age measurement and analysis, were completed on a single sample before the next sample was cut from the parchment. This allowed results from previous measurements to be used to guide later experiments. The AMS measurements were made by methods described in detail elsewhere (Donahue et al. 1990; Jull et al. 1996). As a test of our procedures, we measured the ${ }^{14} \mathrm{C}$ age of several parchments of known age. The Appendix lists details of these tests. Table 1 shows the results of the carbon isotope measurements on parchment from the Vinland Map.

Table $1{ }^{14} \mathrm{C}$ measurements on individual samples of the Vinland Map parchment

\begin{tabular}{llllllll}
\hline $\begin{array}{l}\text { Lab } \\
\text { number }\end{array}$ & $\begin{array}{l}\text { Chemical } \\
\text { process }\end{array}$ & $\begin{array}{l}\text { Run } \\
\text { dates }\end{array}$ & $\begin{array}{l}\text { Mass of } \\
\text { carbon } \\
(\mathrm{mg})\end{array}$ & $\begin{array}{l}\delta^{13} \mathrm{C} \\
\text { per mil }\end{array}$ & $\begin{array}{l}\text { Number of } \\
\text { runs }\end{array}$ & $\begin{array}{l}\text { Average } \\
\text { fraction of } \\
\text { modern }\end{array}$ & $\begin{array}{l}\text { Standard } \\
\text { deviation } \\
( \pm)\end{array}$ \\
\hline $\mathrm{V} 12013$ & $\mathrm{~A}$ & $5 / 95$ & 0.86 & -21.47 & 2 & 1.0176 & 0.005 \\
$\mathrm{~J} 21 \mathrm{~A}$ & $\mathrm{~B}$ & $5 / 95$ & 1.36 & $(-21.9)$ & 2 & 0.9588 & 0.014 \\
$\mathrm{~J} 21 \mathrm{C}$ & $\mathrm{B}$ & $6 / 95$ & 0.62 & -21.89 & 3 & 0.9507 & 0.0035 \\
$\mathrm{~T} 5087$ & $\mathrm{C}$ & $4 / 96$ & 0.7 & $(-21.9)$ & 2 & 0.9353 & 0.006 \\
$\mathrm{~T} 12802$ & $\mathrm{D}$ & $3 / 01$ & 0.69 & -21.91 & 2 & 0.9412 & 0.003 \\
$\mathrm{~J} 44$ & $\mathrm{E}$ & $9 / 95$ & 0.25 & -23.3 & 2 & 0.9310 & 0.008 \\
\hline
\end{tabular}

The Lab numbers given in column 1 indicate the location in our laboratory notebooks at which details of chemical treatments and their results are described. The five chemical procedures used to prepare samples for measurement are indicated in column 2 of the table and are described as follows.

In process $\mathrm{A}$, samples were subjected to a standard acid-base-acid treatment involving aqueous solutions of hydrochloric acid $(\mathrm{HCl})$, dilute sodium hydroxide $(\mathrm{NaOH}),(0.1 \%)$, and $\mathrm{HCl}$ again. To minimize loss of parchment, the sample was treated with base for only a short time.

In process $\mathrm{B}$, before the acid-base-acid treatment, the samples were washed once in acetone in an ultrasonic vibrator for between $30 \mathrm{~min}$ and $1 \mathrm{hr}$. In this wash, samples lost 20 to $30 \%$ of their total mass. In order to insure that masses measured were dry masses, each determination of the mass of a parchment sample was preceded by heating of the sample in a vacuum oven at $50{ }^{\circ} \mathrm{C}$ for $1 \mathrm{hr}$. 
Process $\mathrm{C}$ was similar to process $\mathrm{B}$, but the acetone wash was performed twice. The sample lost $30 \%$ of its mass in the first wash, and no measurable amount in the second wash.

In process $\mathrm{D}$, the sample was initially washed three times in acetone. A loss of $22 \%$ was observed in the first wash, and none in the second and third washes. These multiple acetone washes were performed to demonstrate that one wash was sufficient to remove all of the acetone-soluble contaminant. The acetone washes in process D were followed by washes in, successively, hexane, ethanol, methanol, and distilled water. Finally, in process D, collagen was extracted by washing the parchment in $0.25 \mathrm{~N} \mathrm{HCl}$ and then dissolving it in hot $0.01 \mathrm{~N} \mathrm{HCl}$. The solution was freeze dried, and the resulting collagen was combusted to carbon dioxide, converted to graphite, and analyzed.

In process E, only an acetone wash was used, and the acetone was enriched to $99 \%$ in ${ }^{13} \mathrm{C}$. This process was performed to demonstrate that the water rinses that follow the acetone washes do in fact remove all of the acetone. As can be seen from Table 1, the results for fraction modern and $\delta^{13} \mathrm{C}$ obtained for process $\mathrm{E}$ are in agreement with those for processes B through D. They demonstrate that less than one carbon atom per million in the treated and washed sample was from acetone. In addition to the ${ }^{14} \mathrm{C}$ age and $\delta^{13} \mathrm{C}$ measurements of map parchment washed in ${ }^{13} \mathrm{C}$-enriched acetone, we also measured values for $\delta^{13} \mathrm{C}$ for a separate piece of parchment washed in the enriched acetone. In this case also, the $\delta^{13} \mathrm{C}$ value of the parchment was within 2.3 per mil of the values for parchment treated with normal acetone, confirming the results obtained with the map parchment.

In Table 1, separate results are presented for each target preparation. Two pieces of parchment were prepared by treatment $B$, and one piece was prepared by each of the other treatments. Column 2 of the table indicates the chemical treatment of each target; column 4, the mass of carbon after the combustion; column 5, the $\delta^{13} \mathrm{C}$ of the sample; column 6 , the number of separate accelerator runs performed on each target; and columns 7 and 8, the fraction modern (Donahue et al. 1990), F, and its standard deviation obtained for each target. The values of $\delta^{13} \mathrm{C}$ in column 5 were measured with a stable-isotope mass spectrometer in our laboratory, except for the two given in parentheses. For these, no $\delta^{13} \mathrm{C}$ measurements were available, and the value shown is assumed. The values of $\mathrm{F}$ for each target, given in column 7 in the table, were calculated by averaging the results of the separate runs for each target to obtain a weighted average (Bevington 1992) value for that target. The standard deviations were deduced from the scatter of separate runs from that average, or from the counting statistical error, whichever was larger. All values of $\mathrm{F}$ have been normalized to $\delta^{13} \mathrm{C}=-25.0$ per mil.

An inspection of Table 1 shows that the result for parchment sample \#1 (Chemical treatment A) is quite different from the other results. The fraction modern for this sample is greater than unity. From this we conclude that our parchment had "post-bomb" contamination on it. That is, the parchment was contaminated by ${ }^{14} \mathrm{C}$ produced in atmospheric testing of nuclear devices between 1950 and 1963, and our chemical treatment A was not sufficient to remove all of this contamination. For this reason, we adopted the more rigorous chemical treatments B, C, D, and E described above. The fact that these more rigorous and quite different treatments all gave results in agreement with one another indicates that they were successful in freeing samples 2-6 from contaminants. The considerable time lapse between the first three and the remainder of the measurements was partially due to the fact that considerable effort was made to study the various chemical treatments and to insure that they would successfully remove the post 1950 contaminant. However, quality control over this extended series of measurements was ensured by including sets of identical standards with each determination of fraction modern.

From results presented in Table 1, it is apparent that the age of the parchment from the Vinland Map should be determined only from those measurements with chemical treatments B, C, D, and E. 
These four, quite different, chemical processes result in consistent radiocarbon ages. Of the five measurements, 2 through 6 in Table 1, two are 1.5 sigma, and the others are one sigma or less, from the weighted average. These results give us confidence that the chemical processes removed all contaminants, that measurements made over a period of six years are consistent (as they certainly should be), and that the weighted average of measurements 2 through 6 in Table 1 will yield a correct value for the age of the parchment.

From a comparison of the fraction modern for chemical process A with results from measurements $\mathrm{B}$ through $\mathrm{E}$, and with a knowledge of the approximate amount of contamination removed by the acetone, one can determine that the carbon part of the contamination on the parchment was in the atmosphere sometime close to the period 1958 to 1962 . This is approximately the period during which the map passed from the European rare-book trade into the possession of Yale University. We were not able to study further the properties of this contamination, but we were able to establish that it was all removed in the chemical treatments B through E in Table 1, and thus did not affect the radiocarbon measurements on these samples.

The weighted average of the fraction modern, F, obtained for measurements $2-6$ is

$\mathrm{F}($ weighted average $)=0.9434 \pm 0.0033$.

The error is a standard deviation deduced from the scatter of the five individual measurements from their mean value (Bevington and Robinson 1992). The ${ }^{14} \mathrm{C}$ age of the parchment obtained from this weighted average is

Radiocarbon age $=467 \pm 27 \mathrm{BP}$.

Finally, this ${ }^{14} \mathrm{C}$ age can be converted to calendar-age ranges with the 1998 atmospheric decadal tree ring data set (Stuiver et al. 1998a):

One sigma: cal AD 1423-1445,

Two sigma: cal AD 1411-1468.

A calibrated age range smaller than the standard deviation of the ${ }^{14} \mathrm{C}$ age reflects the fact that the slope of the tree-ring calibration curve in this age region is much steeper than average.

To summarize, results presented here demonstrate that to a 95\% confidence level the carbon of our sample of parchment from the Vinland Map was in equilibrium with atmospheric carbon sometime between AD 1411 and AD 1468. This result is in excellent agreement with the range of ages of the Vinland Map of AD 1431-1449 suggested by R A Skelton, T H Marston, and G D Painter on the basis of their scholarly research (Skelton et al. 1965, 1995).

\section{CONCLUSIONS}

It is important to state once more that the measurements described here determine only the age of the parchment of the Vinland Map and not that of the map itself. However, the age of the parchment is very significant in relation to questions of authenticity and allegations of forgery of the map.

We first note that through much of the 1950 s, the potential of ${ }^{14} \mathrm{C}$ dating was only beginning to be appreciated by a handful of specialists, but was largely unknown to the public. If the map was forged, that forgery obviously had to have occurred before the mid 1950s, when the map's existence became known (Skelton et al. 1965, 1995; Washburn 1971) to a number of independent book dealers and museum curators. However, the crucial step of linking the map to the Council of Basle (1431- 
1449 AD) was only due to the seven-year-long, meticulous scholarly work of Skelton, Marston, and Painter at Yale (1957-1965). Based on the known history of the map, this result could not have been foreseen by a forger. Thus, even if a putative forger had taken ${ }^{14} \mathrm{C}$ dating into account, he could not have had a "target date" of 1434 AD to aim at because that date was not to be established as the appropriate date for the parchment until after the map was acquired. In short, a forger would have had no reason to choose a piece of parchment to insure the date we have found. In light of the above, we are convinced that the precise ${ }^{14} \mathrm{C}$ date of the parchment is significant to the question of the Vinland Map's authenticity.

In 1966, during examination of the 15 th century binding, which was proposed to have originally held the Tartar Relation and the map (Skelton et al. 1965, 1995; Washburn 1971), an "offset" or ink transfer was found hidden under the paste-down end-papers of the binding. This offset related the appointment of the notary Bartholomaeus Poignare (a known historical figure) to the Council of Basle on 16 September 1435 . He served until 4 February 1439 . This offset's date is in striking agreement with our precision ${ }^{14} \mathrm{C}$ one-sigma date of $1434 \pm 11 \mathrm{yr}$.

Our dating research does not prove that the Vinland Map is authentic. We have introduced new evidence that should be addressed in future discussions of the map's authenticity. In view of our ${ }^{14} \mathrm{C}$ data, we feel that declarations of the map's probable forgery should be seriously reevaluated.

\section{ACKNOWLEDGMENTS}

The authors acknowledge the important contributions of T Lange and A J T Jull in developing methods for the chemical treatment of parchment, and the interest and participation in the project of $\mathrm{D}$ van der Reyden, M Schantz, and S Choquette. Research at the Brookhaven National Laboratory is under contract DE-AC02-98-CH 10886 with the Department of Energy. The Arizona AMS laboratory is supported in part by the U.S. National Science Foundation.

\section{REFERENCES}

Bevington PR, Robinson DK. 1992. Data reduction and error analysis for the physical sciences. Second edition. New York: McGraw-Hill.

Bonani G, Ivy S, Wolfli W, Broshi M, Carmi I, Strugnell

J. 1992. Radiocarbon dating of fourteen Dead Sea scrolls. Radiocarbon 34(3):843.

Cahill TA et al. 1987. The Vinland Map, revisited: new compositional evidence on its inks and parchment. Analytical Chemistry 59:829-33.

Donahue DJ, Linick TW, Jull AJT. 1990. Isotope-ratio and background corrections for accelerator mass spectrometry radiocarbon measurements. Radiocarbon 32(2): 135

Jull AJT, Donahue DJ, Broshi M, Tov E. 1995. Radiocarbon dating of scrolls and linen fragments from the Judean Desert. Radiocarbon 37(1):11. See also Atiqot XXVIII (1996).

Magnusson M, Palsson H. 1965. The Vinland Sagas. Harmondsworth: Penguin Books.

McCrone WC. 1974. Report to Yale University on the Vinland Map. Unpublished.

McCrone WC. 1988. The Vinland Map. Analytical Chemistry 60:1009-18.

Olin JS. 2000. Without comparative studies of inks, what do we know about the Vinland Map? Precolumbiana 2(1):27-36.

Olin JS, Towe KM. 1976. Abstracts of the International Congress for the History of Cartography, Washington DC. $\mathrm{p} 25$.

Skelton RA, Marston TE, Painter GD. 1965. The Vinland Map and the Tartar relation. New Haven and London: Yale University Press. First edition.

Skelton RA, Marston TE, Painter GD. 1995. The Vinland Map and the Tartar relation. New Haven and London: Yale University Press. Second edition.

Stuiver M, Reimer PJ, Bard E, Beck JW, Burr GS, Hughen KA, Kromer B, McCormac FG, van der Plicht J, Spurk M. 1998a. INTCAL98 radiocarbon age calibration, 24,000-0 cal BP. Radiocarbon 40(3):104183 , and University of Washington calibration program. Rev. 4.1.2.

Towe KM. 1990. The Vinland Map: still a forgery. Accounts of Chemical Research 23:84-7.

Washburn W, editor. 1971. Proceedings of the Vinland Map conference. Smithsonian Institution, Washington DC, 15-16 November, 1966. Chicago: University of Chicago Press.

Washburn W. In: Skelton RA, Marston TE, Painter GD, editors. 1995. The Vinland Map and the Tartar relation. New Haven and London: Yale University Press. Second edition. $\mathrm{p}$ xxii-xxv. 


\section{APPENDIX}

\section{Tests of our Procedures by ${ }^{14} \mathrm{C}$ Measurements on Documents of Known Date}

Tests of our chemical procedures and isotope analyses were made by performing the same chemical treatments and ${ }^{14} \mathrm{C}$ measurements on parchment samples of known date. Results of these tests are shown in Table 2.

Table $2{ }^{14} \mathrm{C}$ dating tests of parchment manuscripts of known date

\begin{tabular}{|c|c|c|c|c|c|c|c|}
\hline Sample $^{\mathrm{a}}$ & $\begin{array}{l}\text { Fraction } \\
\text { modern after } \\
\text { acid-base-acid }\end{array}$ & $\begin{array}{l}\text { Fraction } \\
\text { modern after } \\
\text { acetone }+ \\
\text { acid-base-acid }\end{array}$ & $\begin{array}{l}\text { Fraction } \\
\text { modern after } \\
\text { collagen } \\
\text { conversion }\end{array}$ & $\begin{array}{l}{ }^{14} \mathrm{C} \\
\text { age (BP) }\end{array}$ & $\begin{array}{l}\text { Calibrated } \\
\text { age, } \mathrm{AD} \\
\text { one sigma }\end{array}$ & $\begin{array}{l}\text { Calibrated } \\
\text { age, } \mathrm{AD} \\
\text { two sigma }\end{array}$ & $\begin{array}{l}\text { Known } \\
\text { age (AD) }\end{array}$ \\
\hline 1 & $0.9508 \pm 0.003$ & & & $405 \pm 25$ & $1444-1482$ & $1437-1620$ & 1434 \\
\hline 1 & & & $0.9332 \pm 0.006$ & $555 \pm 52$ & $1321-1427$ & $1302-1437$ & 1434 \\
\hline 2 & $0.9478 \pm 0.003$ & $0.9462 \pm 0.006$ & & $433 \pm 25^{b}$ & $1438-1466$ & $1427-1485$ & 1446 \\
\hline 3 & $0.9516 \pm 0.003$ & & & $399 \pm 25$ & $1444-1488$ & $1438-1620$ & 1457 \\
\hline 4 & $0.9618 \pm 0.003$ & & & $313 \pm 25$ & $1521-1639$ & $1491-1645$ & 1495 \\
\hline
\end{tabular}

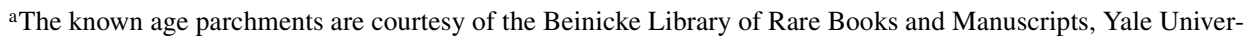
sity. Samples were notary documents from Florence, Italy drawn up on a particular day, month and year known to the Beinicke Library but not to us during the measurements.

${ }^{b}$ Calculated from weighted average. The chemical treatments, fractions modern, radiocarbon ages, and calibrated age-ranges are all as described in the main body of the text. All of the measured results are in reasonable agreement with known ages of the test parchments. Sample \#1 is three years from overlapping the assumed known age at the two-sigma level. Although these Florentine documents were written on precisely known dates, there is a small chance that the parchment employed was somewhat older. At the period of sample \#4 the calibration curve is passing through an unfavorably flat region leading to larger calibration errors. In addition, it should be noted that the Arizona AMS lab (Jull et al. 1995) and the laboratory at Zurich (Bonani et al. 1992) have made many measurements on parchment from Dead Sea Scrolls in which the chemical treatments consisted of washes in various solvents as well as acid-base-acid application. All of these measurements are in reasonable agreement with the paleographic estimates of the ages of the scrolls. These results suggest that radiocarbon measurements can give reliable calendrical date-ranges for manuscripts, contributing one more key piece of evidence to a historiographic or authenticity discussion. 